\title{
Diyabetik Nöropatisi Olan Kişilerde Monosit/HDL Kolesterol Oranı ile Kardiyovasküler Risk
} Arasındaki İlişki

$\underline{\text { Halime Hanım PENCE }}{ }^{1}$, Hanife Serife AKTAS ${ }^{2}$

\begin{abstract}
Öz
Bu çalışmada diyabetin mikrovasküler komplikasyonlarından olan diyabetik nöropatisi olan hastalarda monosit/HDL kolesterol oranı (MHR)'nin kardiyovasküler risk belirteci olup olamayacağının araştırılması amaçlanmıştır. Dahiliye polikliniğimizdeki Ocak 2018-Eylül 2018 tarihleri arasındaki hastalardan 30 diyabetik nöropatisi (DN) olan diyabetes mellitus (DM) hastası, 29 DN olmayan DM hastası ve aynı yaş ve cinsiyette 30 DM olmayan sağlıklı retrospektif olarak çalışmaya alındı. Yaş, cinsiyet, vücut kitle indeksi (BMI), sigara, DM süresi, hipertansiyon, hemogramdaki monosit sayıs1, glikozile hemoglobin Alc (HbAlc), total kolesterol, düşük yoğunluklu lipoprotein LDL kolesterol (LDL-K), yüksek yoğunluklu lipoprotein HDL kolesterol (HDL-K), trigliserid (TG) ve mikroalbuminüri, MHR, Framingham Kardiyovasküler Risk Skorlamasına (FCR) göre olan kardiyovasküler risk oranı incelendi. DN ile DN-olmayan diyabetikler arasında DM süresi açısından fark olduğu görüldü $(p<0,05)$. DN grubun total kolesterol düzeyleri DN-olmayan gruptan $(p<0,05)$ ve kontrol grubundan $(\mathrm{p}<0,01)$ yüksek bulundu. Yine $\mathrm{DN}$ grubun $\mathrm{HbAlc}$ düzeyleri de daha yüksek bulundu $(\mathrm{p}<0,001)$. Kontrol grubunun FCR skorları DN ve DN olmayan gruptan anlamlı şekilde düşüktü $(\mathrm{p}<0,001)$. Grupların MHR'si arasında fark bulunmadı. Tüm hastalarda MHR ile HbA1c, FCR skorları arasında korelasyon bulundu (Spearman's rho $\mathrm{p}$ $<0,05)$. Bu çalışmada diyabetik nöropatisi olan hastalarda MHR'nin kardiyovasküler risk belirteci olabileceği sonucuna ulaşılamamıştır. Ancak tüm hastalarda MHR ile kardiyovasküler risk arasında bir korelasyon görülmüştür. Bu konuda daha geniş serilerde çalışma yapılmasına ihtiyaç vardır.
\end{abstract}

Anahtar kelimeler: Diyabetik nöropati, kardiyovasküler risk, monosit/HDL-K

Yayın Bilgisi

Gönderi Tarihi: 16.09.2019

Kabul Tarihi: 25.09.2019

Online Yayın Tarihi: 31.12.2019

DOI: $10.26453 /$ otjhs.620725

Sorumlu Yazar

Halime Hanım PENÇE

Sağlık Bilimleri Üniversitesi,

Hamidiye Tıp Fakültesi, Tıbbi

Biyokimya Anabilim Dalı, İstanbul.

Tel: :05052183651

E-mail: halime.pence@hotmail.com

\section{The Relationship Between Monocyte / HDL-Cholesterol Ratio and Cardiovascular Risk in}

\section{Diabetic Neuropathia}

\section{$\underline{\text { Halime Hanim PENCE }}{ }^{1},{\underline{\text { Hanife Serife } \mathrm{AKTAS}^{2}}}$}

\begin{abstract}
The aim of this study was to investigate whether monocyte/HDL cholesterol ratio (MHR) could be a marker of cardiovascular risk in patients with diabetic neuropathy which is one of the microvascular complication of diabetes. 30 patients with diabetic neuropathy (DN), 30 patients with non-DN- diabetes mellitus (DM), 30 healthy individuals with non-DM same age and sex in our internal medicine clinic between January 2018-September 2018 were retrospectively studied. Age, gender, body mass index (BMI), smoking, hypertension, the number of monocytes, HbA1c, total cholesterol, low density lipoprotein LDL-cholesterol (LDL-C), high density lipoprotein HDL-cholesterol (HDL-C), triglyceride, microalbuminuria, MHR, Framingham Cardiovascular Risk Scoring (FCR) were investigated. There was a significant difference in the duration of DM between non-DN and diabetic patients $(\mathrm{p}<0.05)$. Total cholesterol levels of DN group were higher than non-DN group ( $\mathrm{p}<0.05)$ and control group $(\mathrm{p}<0.01)$. The FCR scores of the control group were significantly lower than the DN and non-DN groups $(\mathrm{p}<0001)$. There was no difference between MHR and HbAlc and FCR scores in all patients (Spearman's rho $\mathrm{p}<0.05$ ). In this study, we could not conclude that MHR can be a predictor of cardiovascular risk in patients with diabetic neuropathy. However, there was a correlation between cardiovascular risk and MHR in all patients. There is a need for further studies on this subject.
\end{abstract}

Article Info

Received: 16.09.2019

Accepted: 25.09.2019

Online Published: 31.12.2019

DOI: $10.26453 /$ otjhs.620725

Corresponding Author

Halime Hanım PENCE

Sağlık Bilimleri Üniversitesi,

Hamidiye Tıp Fakültesi, Tıbbi

Biyokimya Anabilim Dalı, İstanbul.

Phone:+905052183651

E-mail: halime.pence@hotmail.com

Keywords: Diabetic neuropathy, cardiovascular risk, monocyte/HDL-C

${ }^{1}$ Sağlık Bilimleri Üniversitesi, Hamidiye Tıp Fakültesi, Tıbbi Biyokimya Anabilim Dalı, İstanbul, Türkiye.

${ }^{2}$ Sağlık Bilimleri Üniversitesi, Ümraniye SUAM, İç Hastalıkları Kliniği, İstanbul, Türkiye.

*Bu çalışma Sağlık Bilimleri Üniversitesi 1.Hematoloji Sempozyumu 2018 Kongresi’nde 5.10.2018 tarihinde sözlü bildiri olarak sunulmuş̧ur. 


\section{GíRIȘ}

Diyabetes mellitus kardiyovasküler hastalıkların gelișiminde etkisi olan en önemli risk faktörleri arasında yer alır. ${ }^{1}$ Diyabetik hastalarda görülen mikrovasküler ve makrovasküler komplikasyonlarda endotel disfonksiyonu ve aterosklerozun önemli etkisi vardır. Ayrıca ileri gliko-oksidasyon son ürünlerinin yol açtığı oksidatif stres ve enflamasyonun da bu komplikasyonlara katkısı olduğu bilinmektedir. ${ }^{2}$ Diyabetik hastalarda ortaya çıkan mikrovasküler komplikasyonlar arasında diyabetik nöropati en sik olarak görülenidir. $^{3}$

Yüksek yoğunluklu lipoprotein HDL kolesterol (HDL-K) endotel dokusunu düşük yoğunluklu lipoprotein kolesterolün (LDL-K) zararlı etkilerinden korur ve aynı zamanda LDL-K'ün oksidasyonunu da engeller. Aynı zamanda HDL-K antitrombotik, antienflamatuar ve antioksidan etki de gösterir. ${ }^{4}$ Monositler ve makrofajlar proenflamatuar ve pro-oksidan sitokinlerin sentez ve salınımında önemli rol oynayan hücrelerdir. Son zamanlarda monosit/HDL oranının (MHR) monositlerin proenflamatuar etkisinin yanısıra HDL kolesterolün antienflamatuar ve antioksidan etkilerinden dolayı da enflamasyon ve oksidatif stresin yeni bir belirteci olabileceği düşünülmektedir. ${ }^{5}$ Ayrıca bazı kardiyovasküler hastalıkların varlığı ve prognozu ile de yakından ilişsili olduğu yönünde literatürde çeşitli yayınlar mevcuttur. ${ }^{6}$

$\mathrm{Bu}$ çalıșmada diyabetin mikrovasküler komplikasyonlarından olan diyabetik nöropatisi olan hastalarda MHR ile kardiyovasküler risk arasındaki ilişkinin araştırılması amaçlanmıştır.

\section{MATERYAL VE METOD}

\section{Çalışmanın Dizaynı ve Hastalar}

Hastanemiz dahiliye polikliniğinde Ocak 2018- Eylül 2018 tarihleri arasında takip edilen hastalardan 30 diyabetik nöropatisi (DN) olan diyabetes mellitus (DM) hastas1, 29 DN olmayan DM hastası ve aynı yaş ve cinsiyette $30 \mathrm{DM}$ olmayan sağlıklı retrospektif olarak çalışmaya dahil edildi. Bu çalışma için hastanemiz etik kurulundan onay alınmıştır (B.10.1.TKH.4.34.H.GP.0.01/157).

Çalışmaya dahil edilecek kişiler belirlenirken kronik enfeksiyonu ve malignitesi olmak, geçirilmiş serebrovasküler olay, demans, periferik arter hastalığg, tuzak nöropatiler ve periferik nöropati yol açan diğer hastalıkların varlığı (B12 eksikliği, kronik böbrek hastalığı, amiloidoz, vaskülitler, ALS, ilaca bağlı vs) dışlama kriteri olarak kabul edildi.

\section{Demografik, Tıbbi ve Laboratuvar Verileri}

Çalışmaya dahil edilen kişilerin tıbbi kayıtları retrospektif incelendi ve yaş, cinsiyet, vücut kitle indeksi (BMI), sigara, DM süresi, insülin kullanımı, hipertansiyon öyküsü, statin kullanımı belirlendi. Ayrıca hemogramdaki monosit sayıs1, glikozile hemoglobin A1c 
(HbA1c), total kolesterol, LDL-K, HDL-K, trigliserid (TG) ve mikroalbuminüri düzeyleri de incelemeye alındı. Her hasta için monosit sayısı HDL-K seviyesine bölünerek MHR hesaplandı. Ayrıca her bir hasta için Framingham Kardiyovasküler Risk Skorlamasına (FCR) göre hesaplanmış olan kardiyavasküler risk oranı da belirlendi.

\section{Ístatistiksel Analiz}

Analizler MedCalc Statistical Software version 12.7.7 (MedCalc Software bvba, Ostend, Belgium; http:// www.medcalc.org;2013) programı kullanılarak gerçekleştirilmiştir. Sürekli değişkenleri tanımlamak için deskriptif istatistikler (ortalama, standart sapma, minimum, medyan, maximum) kullanılmıştır. Bağımsız normal dağılıma uygunluk göstermeyen ikiden fazla grup karşılaştırılması Kruskal Wallis testi kullanılarak, bağımsız normal dağılıma uygunluk göstermeyen iki grup karşılaştırması Mann Whitney $\mathrm{u}$ testi kullanılarak yapılmıştır. Normal dağılıma uygunluk göstermeyen iki sürekli değişken arasındaki korelasyon, Spearman Rho korelasyon katsayısı ile incelenmiştir. İstatistiksel anlamlılık düzeyi $\mathrm{p}<0,05$ olarak belirlenmiştir.

\section{BULGULAR}

Çalışma grupları DN olanlar $(n=30), D N$ olmayanlar $(n=29)$ ve diyabeti olmayan kontrol grubu $(n=30)$ olarak belirlendi. $\mathrm{Bu}$ üç grup arasında yaş ortalamaları, cinsiyet, vücut kitle indeksi (BMI), sigara kullanımı açısından farklılık görülmedi (Tablo 1).

DN olanlar ile DN olmayan diyabetikler arasında DM süresi açısından istatistiksel anlamlı farklılık vardır. DN olanların diyabet süresi daha fazla idi $(\mathrm{p}<0,05)($ Tablo 2) .

Grupların total kolesterol düzeyleri arasında istatistiksel olarak anlamlı fark bulundu. DN olan grubun total kolesterol düzeyleri DN olmayan gruptan $(\mathrm{p}<0,05)$ ve kontrol grubundan $(\mathrm{p}<0,01)$ anlamlı şekilde yüksek bulundu. Yine DN olan grubun $\mathrm{HbA1c}$ düzeyleri diğer iki gruptan anlamlı şekilde daha yüksek bulundu $(\mathrm{p}<0,001)$ (Tablo 2) .

Grupların FCR skorları karşılaştırıldığında kontrol grubunun FCR skorları DN olan gruptan $(p<0,001)$ ve $\mathrm{DN}$ olmayan diyabetik gruptan $(\mathrm{p}<0,001)$ anlamlı şekilde düşüktü. Yani diyabetik hastaların FCR skorları daha yüksekti. DN olanlar ile $\mathrm{DN}$ olmayanlar arasında anlamlı skor farkı yoktur (Tablo 2).

Grupların MHR'si karşılaştırıldığında gruplar arasında istatistiksel olarak anlamlı bir fark olmadığ1 görüldü (Tablo 2). Ancak tüm hastalarda MHR ile HbA1c, FCR skorları arasına pozitif yönlü zayıf korelasyon olduğu görüldü (Spearman's rho $\mathrm{p}<0,05$ ) (Tablo 3 ve Sekil 1),

\section{TARTIŞMA}

$\mathrm{Bu}$ çalışmada diyabetik hastalarda kardiyovasküler riskin daha yüksek olduğunu, DN olan kişilerde total kolesterolün daha fazla olduğunu tespit ettik. DN olanlar ile DN 
olmayan diyabetikler arasında MHR'de bir fark olmadığını ancak tüm hastalarda MHR ile HbA1c ve FCR skorları arasında bir korelasyon olduğunu gördük. Diyabetik nöropatisi olan kişilerde MHR'nin kardiyovasküler risk belirteci olarak kullanılabileceği yönünde bir sonuca ulaşamadık.

Diyabetes mellitus kardiyovasküler hastalıkların gelişiminde en önemli risk faktörleri arasında yer alır. $^{7} 1979$ yılında yayınlanan Framingam çalışması 20 yıllık takipler sonrasinda aterosklerotik kardiyovasküler hastalık gelişme oranının diyabetik hastalarda diyabetik olmayanlara göre 2-3 kat arttığını göstermiştir. Kardiyovasküler mortalite diyabetik olmayanlara göre diyabetli erkeklerde 2-3 kat, diyabetli kadınlarda 3-5 kat artmıştır. Tüm diyabetik hasta ölümlerinin \%70-80‘inden kardiyovasküler hastalıklar sorumludur ve bu ölümlerin dörtte üçü koroner arter hastalığına bağlıdır. Diyabetik kardiyomiyopati, hipertansiyon, otonom nöropati ve endotel disfonksiyonu gibi diyabete eşlik eden durumlar dolayısı ile diyabetik hastalarda geç dönem mortalite oranları da diyabetik olmayanlara oranla artmıştır. $^{8}$ Miyokard infarktüsü (MI) gelişme riski diyabetik hastalarda her yaşta artmıştır. $\mathrm{Bu}$ nedenle 'National Cholesterol Education Program Adult Treatment Panel III (NCEP, ATP III) diyabeti kardiyovasküler risk faktörleri içerisinde koroner arter hastalığı eşdeğeri kabul etmiştir. ${ }^{9}$ Diyabetes mellitus, değiştirilemeyen faktörler arasında ateroskleroz açısından en güçlü risk faktörüdür. 5102 diyabetik hasta ile yapılan Birleşik Krallık Prospektif Diyabet Çalışması'ndan (UKPDS) edinilen sonuçlara göre; HbAlc'deki her \%1'lik değer artışı kardiyovasküler hastalık riskini \%10 düzeyinde yükseltmektedir. ${ }^{10}$ Ayrıca glisemik kontrolü iyi olan hastalarda hem mikrovasküler hem de makrovasküler komplikasyonların azaldığı görülmüştür. Benzer şekilde biz de yaptığımız bu çalışmada diyabetik hastalarda kardiyovasküler riskin daha yüksek olduğunu, DN olan hastalarda diyabet süresinin ve $\mathrm{HbAlc}$ düzeylerinin daha fazla olduğunu tespit ettik.

Diyabetes mellitus uzun dönemde mikrovasküler ve makrovasküler komplikasyonların ortaya çıktığı bir hastalıktır. Kan şekeri düzeyine ve diyabetin süresine bağlı olarak kapiller bazal membran kalınlaşması, kapiller geçirgenlik artışı, kan viskozitesinde artış ve trombosit fonksiyonlarında bozulma bu hastalarda mikrovasküler komplikasyonların ortaya çıkmasına neden olmaktadır. Diyabetik nefropati, diyabetik nöropati, diyabetik retinopati bu mikrovasküler komplikasyonlar arasinda yer alır.

Diyabetik nöropati, DM seyrinde ortaya çıkan ve diyabetes mellitusun en s1k görülen 
mikrovasküler komplikasyonudur. Özellikle alt ekstremiteleri etkileyen, periferik, simetrik, sensorinöral bir polinöropati çeşididir. ${ }^{11}$ En sık görülen semptomları; karıncalanma, uyuşma, elektrik çarpması ve özellikle geceleri artan yanma hissidir. Diyabetik nöropatinin prevalansında ve gelişiminde birçok faktör etkilidir. Bunlar arasında diyabet süresi, HbA1c düzeyi, sigara ve erkek cinsiyeti en önemli olanlarıdır. DM'de nöropati prevelansının $\% 5$ ile $\% 60$ arasında olduğunu bildiren çalışmalar vardır. ${ }^{12}$

Diyabetik nöropati diyabetli hastalardaki en önemli morbidite sebeplerinden birisi olmasına rağmen fizyopatolojisinde hala tam aydınlatılamamış noktalar mevcuttur. ${ }^{13}$ Diyabetik nöropati patogenezinin vasküler ve metabolik etkenleri de içeren bir şekilde multifaktöriyel olduğu kabul edilir. Endonöral mikrovasküler yapısal anormallikler, sinirlerdeki kan akımını düzenleyen vazoaktif ajan kusurları, sinir vasküler yapısının otonom innervasyonundaki değişiklikler sinirlerin iskemisine katkıda bulunan faktörler arasında yer alırlar. Ayrica poliol yolunun bozulması, lipid metabolizmasındaki anormallikler, ileri gliko-oksidasyon son ürünlerinin artması ve oksidatif hasar polinöropatiyle ilişkili metabolik faktörler arasında yer alır. ${ }^{14}$

Diyabet mellituslu hastalarda lipid metabolizmasındaki değişikliklerin çok sık olarak görüldüğü ve $\mathrm{DN}$ patogenezine de önemli katkısının olduğu bilinmektedir. Biz de bu çalışmamızda DN olan hastalarda total kolesterol düzeyinin daha yüksek olduğunu tespit ettik.

İnsülin direnci ile artan hepatik lipaz aktivitesi LDL-K ve HDL-K partiküllerindeki fosfolipidleri hidrolize eder ve daha küçük, daha yoğun LDL-K partiküllerinin artmasına, HDL-K'ün azalmasına yol açar. ${ }^{15}$ Diyabetik nöropatili hastalarda genellikle LDL-K ve TG seviyeleri daha yüksek ve HDL-K düzeyi ise daha düşük olduğu için bunun diyabetik nöropati gelişimine etkisi olabileceği ve nörovasküler patolojileri tetikleyeceği düşünülmektedir. Vasa nervorumlarda ateroskleroza bağlı olarak ortaya çıkan mikroanjiopatik değişikliklerin periferik sinirlerin beslenmesini etkileyerek polinöropati oluşumuna aracılık edebilir. ${ }^{16}$ Ayrıca aterojenik dislipideminin bir belirteci olan LDL partikül boyutunun nöropati oluşumu için bağımsız bir risk faktörü olduğu da gösterilmiştir. ${ }^{17}$ Yine başka bir çalışmada artmış olan TG ve LDL-K seviyelerinin sadece son dönem böbrek yetmezliğinin ve diyabetik retinopatinin değil aynı zamanda periferik nöropatinin de progresyonunu hızlandırdığı gösterilmiştir. ${ }^{18}$

HDL-K'un antienflamatuar, antitrombotik ve antioksidan etkileri de olduğu daha önceki çalışmalarda gösterilmiştir. HDL-K, makrofajların lipid yükleri ile arter duvarına lipid taşımasını önleyerek antiaterojenik etki gösterir. Ayrica HDL-K, CD11b 
aktivasyonunun inhibisyonu yoluyla adezyon moleküllerinin endotelial ekspresyonunu inhibe eder ve böylece monositlerin arter duvarına yapışmasını önler. ${ }^{19}$

Lipid metabolizmasındaki değişiklikler diyabetli hastalarda düşük dereceli enflamasyonla eş zamanlıdır. Daha önceki çalışmalarda diyabetik hastalarda C-reaktif protein (CRP), interlökin (IL)-1, IL-6, tümör nekroz faktörü alfa (TNF- $\alpha)$ ve enflamatuar sitokin seviyelerinin daha yüksek olduğu

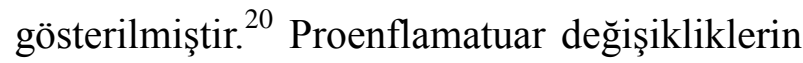
nefropati, nöropati ve ateroskleroz gibi komplikasyonların patogenezinde doğrudan rolü vardır. ${ }^{21}$

Çok sayıda hastalıkta klinik bulgular, morbidite ve mortalitenin potansiyel belirleyicileri olduğu düşünülen lökositer seri hücreleri ile onun subtipleri enflamasyon belirteci olarak yaygın şekilde kullanılmaktadırlar. IL-1, IL-6, IL-18, TNF- $\alpha$, interferon-1, transforme büyüme faktörü-1 ve CRP diyabetin patogenezi ile ilişkili enflamatuar faktörlerdir. ${ }^{22}$ Dolaşımdaki bu faktörler düşük dereceli kronik infamasyonu yansitır ve diyabetik komplikasyonlarla ilişkilidir. $^{23}$ Ancak günlük klinik uygulamalarda bu belirteçlerin tespit edilmeleri yüksek maliyetleri nedeniyle mümkün olamamaktadır. $\mathrm{Bu}$ durumda $\mathrm{MHR}$ gibi daha düşük maliyete ve ölçüm kolaylığına sahip olan belirteçler, enflamasyonun bir göstergesi olarak giderek daha fazla kabul görmekte ve üzerinde araştırmalar yoğunlaşmaktadır.

Proenflamatuar sitokin sekresyonunu indükleyen ve enflamatuar bir hastalık olan aterosklerozun oluşumunda rol oynayan hücre tipi monositlerdir. Diyabetik hastalardaki hiperglisemi monositleri aktive eder. Hiperglisemi ayrıca oksidatif strese neden olur, bu da lipid peroksidasyonu, proenflamatuar faktörlerin indüklenmesi, hücresel antioksidanların tüketilmesi ve onarım mekanizmalarının patolojik aktivasyonu yoluyla sinir hücrelerine zarar verir. $\mathrm{Bu}$ nedenle MHR'nin monositlerin proenflamatuar etkisinin yanısıra HDL kolesterolün antienflamatuar ve antioksidan etkilerinden dolayı da iltihabı gösterebileceği düşünülmektedir. ${ }^{24}$

Yeni enflamatuar bir belirteç olan MHR ile ilgili son yıllarda yapılmış olan çeşitli çalışmalar vardır. Canpolat ve arkadaşları yükssek MHR'nin yavaş koroner fenomen ile ilişkili olduğunu, ${ }^{25}$ Kundi ve arkadaşları koroner arter hastalığı olan kişilerde MHR ile SYNTAX skoru arasındaki ilişkiyi, ${ }^{26}$ Karataş ve arkadaşları artmış MHR'nin diyabetik nefropati için biyomarker olabileceğini tespit etmişlerdir. ${ }^{27}$ Aydın ve arkadaşları primer hipertansiyonu olan hastalarda MHR'nin asemptomatik organ hasarı ile arasında ilişki olduğunu, ${ }^{28}$ Çetin ve arkadaşları ise akut koroner sendromu olan hastalarda MHR'nin koroner arter hastalığının 
ciddiyetinin ve gelecekteki majör kardiyovasküler olayların bağımsız bir göstergesi olduğunu söylemişlerdir. ${ }^{29}$

Vural ve arkadaşları da yaptıkları çalışmada diyabetik aksonal polinöropatisi olan hastalarda MHR düzeylerinin daha yüksek olduğunu ve MHR'nin diyabetik nöropati için belirleyici olarak olarak kullanılabileceğini belirtmişlerdir. $^{30}$ Ancak biz yaptığımız bu çalışmada DN olanlar ile DN olmayanlar arasında MHR yönünden bir fark tespit etmedik. Ayrıca DN hastaları için kardiyovasküler risk belirteci olabileceği yönünde bir sonuca varamadik. Ancak tüm hastalarda MHR ile kardiyovasküler risk arasında bir korelasyon olduğunu tespit ettik. MHR ile ilgili tüm bu veriler dikkate alındığında MHR ile kardiyovasküler olaylar arasında bir ilişki olduğunu düşündürmektedir. $\mathrm{Bu}$ konu üzerinde yapılacak geniş hasta serilerindeki ileriye dönük uzun süreli çalışmalardan daha güçlü kanıtlara ulaşılabilir.

Çalışmanın Kısıtlılıkları: Çalışmamızda çeşitli sınırlamalar mevcuttu. Bunlardan birisi çalışmanın retrospektif olarak tasarlanmış olmasıdır. Diğeri ise çalışmadaki hasta sayısının az olmasıdır. Gelecekteki diyabetik nöropati ve kardiyovasküler olaylar ile MHR arasındaki ilişkiyi araştıran çalışmalar daha geniş hasta serilerinde prospektif olarak tasarlanmalıdır.
Sonuç: Bu çalışmada diyabetik nöropatisi olan hastalarda MHR'nin kardiyovasküler risk belirteci olabileceği yönünde bir sonuca ulaşılamamıştır. Ancak tüm hastalarda MHR ile kardiyovasküler risk arasında bir korelasyon görülmüştür. Bu konuda daha geniş serilerde çalışma yapılmasına ihtiyaç vardır.

\section{KAYNAKLAR}

1. Dokken BB. The Pathophysiology of Cardiovascular Disease and Diabetes: Beyond Blood Pressure and Lipids. Diabetes Spectrum. 2008;21(3):160-165. doi: 10.2337/diaspect.21.3.160.

2. Oto A. Diabet ve Koroner Arter Hastalığı: Gelişen Dünyanın Korkunç İkilisi. Türkiye Kardiovasküler Tıp Elektronik Dergisi. 2007 Nov. Avaible from: http://www. Turkkardiyovaskulertipe-dergisi.com Last Access: 16th May 2011.

3. Bansal V, Kalita J, Misra UK. Diabetic neuropathy. Postgrad Med J. 2006;82:95100.

4. Barter PJ, Nicholls S, Rye KA, et al. Antiinflammatory properties of HDL. Circ Res. 2004;95:764-772.

5. Negi G, Kumar A, Joshi RP, et al. Oxidative stress and Nrf2 in the pathophysiology of diabetic neuropathy: old perspective with a new angle. Biochem and Biophys Res Commun. 2011;408:1-5.

6. Kızıltunç E, Alsancak Y, Sezenöz B, et al. Relationship Between Monocyte/High- 
Density Lipoprotein Cholesterol Ratio and Angiographic Severity and Extent of Coronary Artery Disease. Koşuyolu Heart J. 2017;20(1):30-35.

7. Charnogursky GA, Emanuele NV, Emanuele MA. Neurological complications of diabetes. Curr Neurol Neurosci Rep. 2014;14:457:1-16.

8. Johnstone MT, Nesto R. Diabetes mellitus and heart disease. In: Pickup JC, Williams G, editors. Joslin's Diabetes Mellitus. 14th ed. Philadelphia: Lippincott Williams and Wilkins; 2005:975- 998.

9. Expert Panel on Detection, Evaluation, and Treatment of High Blood Cholesterol in Adults. Executive Summary of The Third Report of The National Cholesterol Education Program (NCEP) Expert Panel on Detection, Evaluation, And Treatment of High Blood Cholesterol In Adults (Adult Treatment Panel III). JAMA. 2001; 285: 2486-2497.

10. UK Prospective Diabetes Study (UKPDS) Group. Intensive blood-glucose control with sulfonylureas or insulin compared with conventional treatment and risk of comlications in patients with type 2 diabetes. Lancet 1998;352:854-65.

11. Katulanda $P$, Ranasinghe $P$, Jayawardena $\mathrm{R}$, et al. The prevalence, patterns and predictors of diabetic peripheral neuropathy in a developing country. Diabetol Metab
Syndr. 2012;4:21:1-8. doi: 10.1186/17585996-4-21.

12. Perez-Matos MC, Morales-Alvarez MC, Mendivil CO. Lipids: a suitable therapeutic target in diabetic neuropathy. J Diabetes Res. 2017:6943851:1-9. doi: $10.1155 / 2017 / 6943851$.

13. Krauss RM. Lipids and lipoproteins in patients with type 2 diabetes. Diabetes Care. 2004;27:1496-1504.

14. Çomoğlu S, Yardımcı S, Okçu Z. The alterations in plasma lipid profile of diabetic polyneuropathic patients. T Klin $\mathrm{J}$ Med Sci. 2001;21:345-348.

15. Isomaa $B$, Henricsson $M$, Almgren $P$, et al. The metabolic syndrome influences the risk of chronic complications in patients with Type II diabetes. Diabetologia. 2001;44:1148-1154.

16. Obrosova IG, Ilnytska O, Lyzogubov VV, et al. High-fat diet induced neuropathy of pre-diabetes and obesity: effects of "healthy" diet and aldose reductase inhibition. Diabetes. 2007;56:2598-2608.

17. Murphy AJ, Woollard KJ, Hoang A, et al. High density lipoprotein reduces the human monocyte inflammatory response. Arterioscler Thromb Vasc Biol. 2008;28:2071-2077.

18. Garcia C, Feve B, Ferré $P$, et al. Diabetes and inflammation: fundamental aspects and clinical implications. Diabetes Metab. 2010;36:327-338. 
19. Skundric DS, Lisak RP. Role of neuropoietic cytokines in development and progression of diabetic polyneuropathy: from glucose metabolism to neurodegeneration. Exp Diabesity Res. 2003;4:303-312.

20. Lim AK, Tesch GH. Inflammation in diabetic nephropathy. Mediators Inflamm. 2012:146154:1-12.

21. Blüher $M$, Unger $R$, Rassoul $F$, et al. Relation between glycaemic control, hyperinsulinaemia and plasma concentrations of soluble adhesion molecules in patients with impaired glucose tolerance or Type II diabetes. Diabetologia. 2002;45:210-216.

22. Hilgendorf I, Swirski FK, Robbins CS. Monocyte fate in atherosclerosis. Arterioscler Thromb Vasc Biol. 2015;35:272-279.

23. Nandy D, Janardhanan R, Mukhopadhyay D, et al. Effect of hyperglycemia on human monocyte activation. $\mathbf{J}$ Investig Med. 2011;59:661-667.

24. Negi G, Kumar A, Joshi RP, et al. Oxidative stress and Nrf2 in the pathophysiology of diabetic neuropathy: old perspective with a new angle. Biochem and Biophys Res Commun. 2011;408:1-5.

25. Canpolat U, Çetin EH, Cetin S, et al. Association of monocyte-to-HDL cholesterol ratio with slow coronary flow is linked to systemic inflammation. Clin Appl Thromb Hemost. 2016;22:476-482.

26. Kundi H, Kiziltunc E, Cetin M, et al. Association of monocyte/HDL-C ratio with SYNTAX scores in patients with stable coronary artery disease. Herz. 2016;41:523-529.

27. Karatas A, Turkmen E, Erdem E, Dugeroglu H, Kaya Y.Monocyte to highdensity lipoprotein cholesterol ratio in patients with diabetes mellitus and diabetic nephropathy.Biomark Med. 2018;12(9): 953-959.

28. Aydin E, Ates I, Arikan MF, Yilmaz $\mathrm{N}$, Dede F.The ratio of monocyte frequency to HDL cholesterol level as a predictor of asymptomatic organ damage in patients with primary hypertension. Hypertens Research. 2017;40(8):758-764.

29. Cetin MS, Cetin EH, Kalender E, et al. Monocyte to HDL Cholesterol Ratio Predicts Coronary Artery Disease Severity and Future Major Cardiovascular Adverse Events in Acute Coronary Syndrome. Heart Lung Circ. 2016;25(11):1077-1086.

30. Vural G.,Gümüşyayla Ş., Monocyte-to-high density lipoprotein ratio is associated with a decreased compound muscle action potential amplitude in patients with diabetic axonal polyneuropathy. Medicine (Baltimore). 2018;97(42). 
Tablo 1. Demografik Özelliklerin Gruplara Göre Değerlendirmesi.

\begin{tabular}{|c|c|c|c|c|c|}
\hline & & $\begin{array}{l}\text { DN } \\
\text { Ort } \pm \text { SS } \\
\mathbf{n}=\mathbf{3 0}\end{array}$ & $\begin{array}{l}\text { DN olmayan } \\
\text { Ort } \pm \text { SS } \\
\text { n=29 }\end{array}$ & $\begin{array}{l}\text { Kontrol } \\
\text { Ort } \pm \text { SS } \\
n=30 \\
\end{array}$ & ${ }^{1} \mathbf{p}$ \\
\hline Yaș (yıl) & & $56,85 \pm 9,87$ & $55,39 \pm 8,84$ & $53,14 \pm 9,24$ & 0,42 \\
\hline BMI $\left(\mathrm{kg} / \mathrm{m}^{2}\right)$ & & $\begin{array}{l}32,52 \pm 7,10 \\
\mathbf{n}(\%)\end{array}$ & $\begin{array}{l}30,52 \pm 4,42 \\
\text { n }(\%)\end{array}$ & $\begin{array}{l}31,26 \pm 6,21 \\
\mathbf{n}(\%)\end{array}$ & $\begin{array}{l}0,410 \\
2 p\end{array}$ \\
\hline Cinsiyet & $\begin{array}{l}\text { Erkek } \\
\text { Kadın }\end{array}$ & $\begin{array}{l}7(\% 25,9) \\
23(\% 74,1)\end{array}$ & $\begin{array}{l}13(\% 43,5) \\
16(\% 56,5)\end{array}$ & $\begin{array}{l}11(\% 33,3) \\
19(\% 66,7)\end{array}$ & 0,425 \\
\hline Sigara & $\begin{array}{l}\text { Yok } \\
\text { Var }\end{array}$ & $\begin{array}{l}21(\% 70,4) \\
9(\% 29,6)\end{array}$ & $\begin{array}{l}21(\% 73,9) \\
8(\% 26,1)\end{array}$ & $\begin{array}{l}20(\% 66,7) \\
10(\% 33,3)\end{array}$ & 0,871 \\
\hline HT & $\begin{array}{l}\text { Yok } \\
\text { Var }\end{array}$ & $\begin{array}{l}7(\% 22,2) \\
23(\% 77,8)\end{array}$ & $\begin{array}{l}13(\% 43,5) \\
16(\% 56,5)\end{array}$ & $\begin{array}{l}12(\% 47,6) \\
18(\% 52,4)\end{array}$ & 0,137 \\
\hline Vask. H. & $\begin{array}{l}\text { Yok } \\
\text { Var }\end{array}$ & $\begin{array}{l}22(\% 81,5) \\
5(\% 18,5)\end{array}$ & $\begin{array}{l}20(\% 87) \\
3(\% 13)\end{array}$ & $\begin{array}{l}21(\% 100) \\
0(\% 0)\end{array}$ & 0,125 \\
\hline
\end{tabular}


Tablo 2. Klinik Parametrelerin Gruplara Göre Değerlendirmesi.

\begin{tabular}{|c|c|c|c|c|}
\hline & $\begin{array}{l}\text { DN } \\
\text { n=30 } \\
\text { Ort. } \pm \text { SS } \\
\text { Med. (Min.-Maks.) }\end{array}$ & $\begin{array}{l}\text { DN olmayan } \\
\text { n=29 } \\
\text { Ort. } \pm \text { SS } \\
\text { Med. (Min.-Maks.) }\end{array}$ & $\begin{array}{l}\text { Kontrol } \\
\text { n=30 } \\
\text { Ort. } \pm \text { SS } \\
\text { Med. (Min.-Maks.) }\end{array}$ & $\mathbf{P}$ \\
\hline Dm Süre & $\begin{array}{l}8,19 \pm 4,25 \\
8(1-20)\end{array}$ & $\begin{array}{l}5,9 \pm 4,92 \\
4(1-20)\end{array}$ & - & $\mathbf{0 , 0 3 2} *$ \\
\hline HbA1c & $\begin{array}{l}8,17 \pm 1,7 \\
7,8(5,8-11,6)\end{array}$ & $\begin{array}{l}7,38 \pm 1,51 \\
7,02(5,7-10,7)\end{array}$ & $\begin{array}{l}5,52 \pm 0,31 \\
5,5(5,1-6,4)\end{array}$ & $<0,001$ \\
\hline Mono(300-900) & $\begin{array}{l}504,44 \pm 146,56 \\
500(220-720)\end{array}$ & $\begin{array}{l}506,65 \pm 168,05 \\
480(260-910)\end{array}$ & $\begin{array}{l}458,1 \pm 126,87 \\
410(270-730)\end{array}$ & 0,431 \\
\hline $\mathbf{M} / \mathbf{H r}$ & $\begin{array}{l}13,05 \pm 5,71 \\
12,7(5,09-25,4)\end{array}$ & $\begin{array}{l}12,21 \pm 4,63 \\
12,11(3,82-20,9)\end{array}$ & $\begin{array}{l}10,74 \pm 4,63 \\
9,26(5,4-20,6)\end{array}$ & 0,265 \\
\hline HDL-K & $\begin{array}{l}42,52 \pm 13,8 \\
42(23-79)\end{array}$ & $\begin{array}{l}43,3 \pm 8,84 \\
44(29-68)\end{array}$ & $\begin{array}{l}45,33 \pm 11,21 \\
42(29-68)\end{array}$ & 0,611 \\
\hline LDL-K & $\begin{array}{l}148,68 \pm 41,63 \\
151(86-233)\end{array}$ & $\begin{array}{l}130,39 \pm 25,87 \\
124(88-189)\end{array}$ & $\begin{array}{l}123,95 \pm 34,71 \\
122(60-178)\end{array}$ & 0,124 \\
\hline T.Kol & $\begin{array}{l}236,78 \pm 44,25 \\
237(153-325)\end{array}$ & $\begin{array}{l}208,26 \pm 31,45 \\
197(150-274)\end{array}$ & $\begin{array}{l}195,76 \pm 41,14 \\
190(115-249)\end{array}$ & 0,002 \\
\hline FCR Risk \% & $\begin{array}{l}24,02 \pm 7,83 \\
30(8,6-30)\end{array}$ & $\begin{array}{l}23,48 \pm 7,04 \\
25(4,5-30)\end{array}$ & $\begin{array}{l}10,79 \pm 9,34 \\
9,25(1-30)\end{array}$ & $<0,001$ \\
\hline Mikroalbumin & $\begin{array}{l}146,37 \pm 222,52 \\
29(5-680)\end{array}$ & $\begin{array}{l}50,48 \pm 83,41 \\
16(5-307)\end{array}$ & $\begin{array}{l}9,19 \pm 8,72 \\
5(3-40)\end{array}$ & $<0,001$ \\
\hline
\end{tabular}

*Kruskal Wallis(Mann-Whitney U); HDL-K:HDL-Kolesterol; LDL-K: LDL-Kolesterol; T.Kol: Total Kolesterol; FCR Risk: Framingham Kardiyovasküler Risk Skorlamast; DN:Diyabetik Nöropati; M/Hr:Monosit/HDL-Kolesterol orani; Dm Süre: Diyabet Mellitus tanısindan sonra geçen süre. 
Tablo 3. MHR ile diğer parametrelerin korelasyonu.

\begin{tabular}{|c|c|c|c|c|c|}
\hline MHR* & & DN olmayan & $\mathbf{D N}$ & Kontrol & Tüm hastalar \\
\hline \multirow[t]{2}{*}{ HbA1c } & $\mathbf{r}$ & 0,264 & 0,136 & $-0,007$ & 0,261 \\
\hline & $\mathbf{p}$ & 0,223 & 0,500 & 0,978 & 0,028 \\
\hline \multirow[t]{2}{*}{ Mono(300-900) } & $\mathbf{r}$ & $\mathbf{0 , 8 7 0}$ & 0,607 & 0,717 & 0,790 \\
\hline & $\mathbf{p}$ & $<0,001$ & 0,001 & $<0,001$ & $<0,001$ \\
\hline \multirow[t]{2}{*}{ HDL-K } & $\mathbf{r}$ & $-0,578$ & $-0,740$ & $-0,776 * *$ & $-0,677$ \\
\hline & $\mathbf{p}$ & 0,004 & 0,001 & $\mathbf{0 , 0 0 1}$ & $<0,001$ \\
\hline \multirow[t]{2}{*}{ LDL-K } & $\mathbf{r}$ & $-0,139$ & $-0,242$ & 0,155 & $-0,082$ \\
\hline & $\mathbf{p}$ & 0,527 & 0,278 & 0,514 & 0,517 \\
\hline \multirow[t]{2}{*}{ T.Kol } & $\mathbf{r}$ & $-0,146$ & $-0,078$ & 0,057 & 0,005 \\
\hline & $\mathbf{p}$ & 0,507 & 0,699 & 0,808 & 0,969 \\
\hline \multirow[t]{2}{*}{ FCR Risk \% } & $\mathbf{r}$ & 0,330 & 0,143 & 0,231 & $\mathbf{0 , 3 0 1}$ \\
\hline & $\mathbf{p}$ & 0,124 & 0,477 & 0,328 & $\mathbf{0 , 0 1 1}$ \\
\hline \multirow[t]{2}{*}{ Mikroalb. } & $\mathbf{r}$ & 0,167 & $-0,055$ & 0,119 & 0,183 \\
\hline & $\mathbf{p}$ & 0,446 & 0,785 & 0,606 & 0,126 \\
\hline \multirow[t]{2}{*}{ Sistolik tansiyon } & $\mathbf{r}$ & $-0,213$ & $-0,041$ & 0,027 & $-0,047$ \\
\hline & $\mathbf{p}$ & 0,329 & 0,838 & 0,907 & 0,697 \\
\hline \multirow[t]{2}{*}{ Diastolik tansiyon } & $\mathbf{r}$ & 0,038 & $-0,002$ & $-0,022$ & $-0,009$ \\
\hline & $\mathbf{p}$ & 0,864 & 0,992 & 0,925 & 0,942 \\
\hline
\end{tabular}




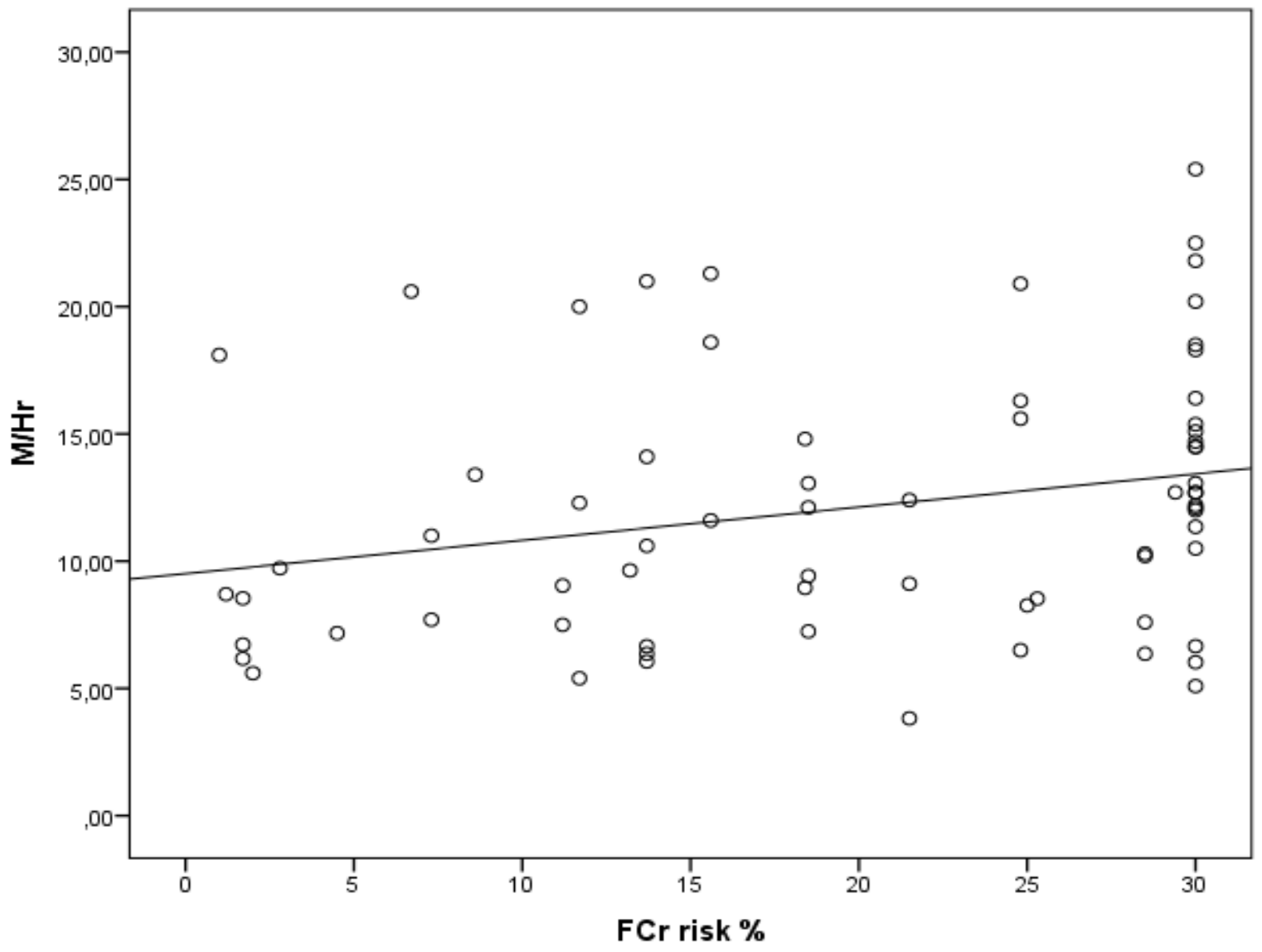

Şekil 1. MHR ile FCR arasındaki korelasyon grafiği. 